\title{
Inhalt der 3. Lieferung
}

\section{Vorbemerkungen zu $\$ \S 43-48$ : Recht der Versicherungsvermittlung}

I. Begriff der Vsvermittlung Anm. 1-11 . . . . . . . . . . . 536-539

Schrifttum Anm. 1 . . . . . . . . . . . . . . . . . 536

1. Geschichte Anm. 2 . . . . . . . . . . . . . . . 537

2. Ausscheidung Anm. 3-9 . . . . . . . . . . . . . . . . . . . 537-539

3. Wesen Anm. 10. . . . . . . . . . . . . . . . . . . . 539

4. Vermittlung Anm. 11 . . . . . . . . . . . . . 539

II. Arten der Vsvermittler Anm. 12-28 . . . . . . . . . . . . . . . 539-549

1. Haupttypen Anm. 13-23 . . . . . . . . . . . . . . . . . . . 539-548

2. Zwischengebilde Anm. 24-28 . . . . . . . . . . . . . . . . . 548-549

III. Recht der Vsmakler Anm. 29-126 . . . . . . . . . . . . . . . . 550-587

1. Begriff des Vsmaklers Anm. 30 . . . . . . . . . . . . . . 552

2. Arten des Vsmaklers Anm. 31-33 . . . . . . . . . . . . . . . 552-553

3. Rechtsquellen des Maklerrechts Anm. 34-36 . . . . . . . . . . 553-555

4. Rechtsstellung des Handelsmaklers Anm. 37-120 . . . . . . . . 555-586

5. Rechtsstellung des Zivilmaklers Anm. 121-126 . . . . . . . . . 586-587

IV. Recht der Vsvertreter Anm. 127-139 . . . . . . . . . . . . . . 588-609

Schrifttum Anm. 127 . . . . . . . . . . . . . . . . . . 588

1. Begriff des Vsvertreters Anm. 128-130. . . . . . . . . . . . 588

2. Arten des Vsvertreters Anm. 131-132 . . . . . . . . . . . 589

3. Rechtsquellen des Vertreterrechts Anm. 133-138 . . . . . . . . 589-609

4. Innen- und Außenverhältnis Anm. 139 . . . . . . . . . . . . . 609

V. Speziell: Innenverhältnis der Vsvertreter Anm. 140-220 . . . . . . 610-671

1. Innenverhältnis bei selbständigen Vsvertretern Anm. 140-220 . . 615-671

\section{Abkürzungen}

Die Abkürzungen für die gebräuchlichsten Allgemeinen Versicherungsbedingungen (AVB) sind eingeführt in der Einleitung Anm. 20 (Lieferung 1).

Das wichtigste Schrifttum ist mit der benutzten Zitierweise angeführt in der Einleitung Anm. 39 (Lieferung 1). - Ist ein Werk mit dem Zusatz a. a. O. zitiert, so ist der genaue Fundort aus den Schrifttumsangaben des betreffenden Abschnitts zu entnehmen.

Ferner bedeuten: $\mathrm{V}=$ Versicherung, $\mathrm{Ver}=$ Versicherer, Vmer $=$ Versicherungsnehmer, Vter $=$ Versicherter.

Ein ausführliches Abkürzungsverzeichnis wird der letzten Lieferung beigefügt sein. 